\title{
Fenologi Mangrove (Rhizophora apiculata, $R$. mucronata dan R.stylosa) di Pulau Unggas, Air Bangis Pasaman Barat, Sumatera Barat
}

\author{
Eni Kamal \\ Fakultas Perikanan dan Ilmu Kelautan, Universitas Bung Hatta, Padang 25133 \\ Diterima 22-10-2010Ｄisetujui 24-01-2011
}

\begin{abstract}
Phenology of tropical forest plant is a population factor and does not include community factor, this is caused by a genetic determination and also the influence of the environment. Phenology of plants in mangrove correlated with the time of flowering, fruiting, and production of fruits or propagules. Phenology research in mangrove plants in the Unggas Island, West Pasaman, done with 'tagging' technique method. Signs made of plastic and are numbered. Data collection included from the formation of flower blooming, up to the formation of fruit or propagules ripe. Phase of the development is categorized to two categories: (a) flower, and (b) fruit. The analysis method is the analysis of variance (ANOVA, p<0.01) and post-hoc test, Duncans Multiple Range Test (DMRT, p<0.01) to obtain comparison and differences between the components of flower, flower fall, fruit, and fruit maturity.
\end{abstract}

Keywords: flower, fruit, mangrove, Phenology, Pulau Unggas

\section{PENDAHULUAN}

Fenologi pada tumbuhan bakau berhubungan dengan waktu berbunga, berbuah dan produksi buah/propagul dimana pada tumbuhan bakau dimulai dengan terbentuknya bagian vegetatif (primordial) bunga yang melalui proses pertumbuhan akan menjadi bagian generatif yaitu buah atau propagul. Mengetahui dan mempelajari pembungaan pada tumbuhan bakau (mangrove) adalah sangat penting, terutama untuk mengetahui tingkat regenerasi pada saat menanam kembali hutan bakau, jika kalau terjadi kerusakan secara menyeluruh, baik disebabkan oleh faktor alam maupun faktor kebijakan yang diambil pada kawasan tempat tumbuhan hutan bakau.

Chan et al. (1993), dari hasil penelitiannya di hutan bakau Kelang, Malaysia bahwa telah diketahui kisaran reproduksi tumbuhan bakau (reproductive cycle duration) mulai dari terbentuknya bunga (inflorescence) sampai buah matang (propagule fall) pada Rhizophora apiculata adalah 32 bulan dan fase perkembangan yang lama terjadi pada saat terbentuknya bakal bunga ke tunas (buds) adalah 18 bulan dan dari tunas ke antesis 8,7 bulan. Di Bali $R$. apiculata waktu terbentuknya dari bakal bunga sampai menghasilkan buah adalah 22,30 bulan (Kitamura et al. 1997).

Pengamatan pada penelitian ini dilakukan dari mulai berbunga, keluarnya kuncup bunga pertama sampai pada waktu bunga terakhir, waktu bakal buah pertama, dan terbentunya pentil (bakal) buah pada bunga, dan waktu buah matang. Bunga dan buah bisa saja tetap tinggal pada tumbuhan selama satu tahun atau lebih, seperti yang terjadi pada Avicennia africana, di mana buah tetap berada pada pohonnya sampai bijinya bercambah di pohon tersebut.

Penelitian ini dilakukan untuk menganalisis fase perkembangan bunga dan buah, produksi buah atau propagul pada setiap spesies $R$. apiculata, $R$. mucronata, dan $R$. stylosa tumbuhan bakau yang tumbuh di Pulau Unggas Air Bangis, Pasaman Barat, Sumatra Barat.

\section{BAHANDANMETODE}

Penelitian fenologi mangrove telah dilaksanakan di Pulau Unggas, Air Bangis, Pasaman Barat. Kawasan Pulau ini terletak pada $0^{\circ} 15^{\prime} 27.4^{\prime \prime}$ lintang utara dan $99^{\circ} 18^{\prime} 0.54^{\prime}$ " bujur timur, dan merupakan sebuah Pulau kecil yang terletak pada muara sungai Batang Tomak Air Bangis, di bagian timur berbatasan dengan muara sungai dan bahagian baratnya berbatasan dengan laut. Lama pengambilan sampel adalah 2 tahun, yaitu mulai Januari 2008 sampai Desember 2009.

Pengambilan dan pencatatan sampel dilakukan setiap bulan. Pencatatan sampel dilakukan dengan tujuan untuk mendapatkan data-data sebagai berikut ; (1) awal pembentukan bakal tunas "Inflorescence formation", (2) jumlah bunga awal yang ditemukan pada pencatatan pertama dan pertambahan bunga setiap bulan, (3) jumlah bunga berkembang dan tidak berkembang, (4) jumlah bunga jatuh, (5) Waktu yang diperlukan dari perkembangan bunga ke buah, (6) Jumlah bunga yang menjadi bakal buah, (7)

\footnotetext{
*Telp: +6281363389898

Email: ekamal898@yahoo.com
} 
Jumlah buah jatuh dan jumlah buah tinggal yang membentuk propagul, (8) ukuran bunga, buah dan propagul, (9) jumlah propagul masak yang masih tinggal pada batang, (10) bentuk propagul tumbuh (bengkok, bercabang, hanyut dan lain), dan (11) jumlah propagul hidup dan mati dan kerusakan yang terjadi.

Metode yang digunakan adalah dengan teknik penandaan "tagging". Tanda dibuat dari plastik dan diberi nomor. Jumlah batang sampel mangrove adalah 10 untuk setiap spesies dan dilakukan secara acak. Pada batang mangrove sampel pertama diberi tanda bernomor 1 sampai 10 yang diletakan pada ranting tempat bunga muncul, batang mangrove sampel kedua diberi nomor 11-20, dan sampai pada batang mangrove sampel ke sepuluh di tandai dengan nomor 91-100 (Gambar 1).

Pengamatan bunga dimulai dari mulai terbentuknya atau munculnya bakal bunga sampai ke pembentukan buah/ propagul matang. Dalam pengamatan tersebut dibagi kepada dua kategori yaitu (1) bunga adalah di awali oleh kemunculan tunas pada promordia, pucuk tunas terbentuk, kemunculan bakal bunga, kemunculan tunas bunga di dalam kelopak bunga (calyx), berkembangnya tunas bunga dan bunga terbuka, (2) buah adalah di mulai dengan kemunculan hipokotil, hipokotil berkembang, dan propagul matang. Untuk memudahkan pencatatan setiap kategori perkembangannya di ambil gambar pada masing-masing kategori tersebut.

Analisis yang digunakan adalah analisis varian (ANOVA, $\mathrm{p}<0,01$ ) dan uji post-hoc Duncans Multiple Range Test (DMRT, $\mathrm{p}<0,01)$.

\section{HASIL DAN PEMBAHASAN}

Ciri umum bunga $R$. apiculata. $R$. apiculata mempunyai bunga biseksual, kepala bunga kekuningkuningan yang terletak pada gagang yang berukuran 0,50 sampai $1,00 \mathrm{~cm}$. Bunga berada di ketiak daun, formasi bunga berkelompok (2 bunga per kelompok), kelopak bunga

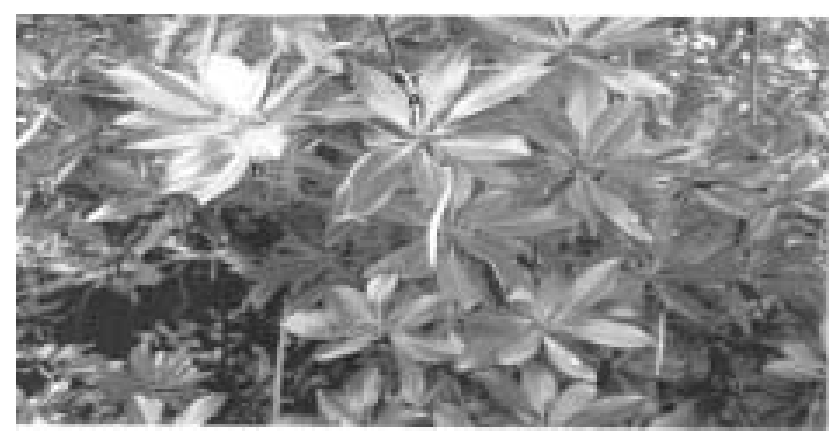

Gambar 1 Penandaan pada ranting $R$. mucronata di kawasan Pulau Unggas Air Bangis, Pasaman Barat. A- Ranting dan BNomor tanda berwarna kuning kecoklatan, melengkung, banyak benang sari 11-12 dan tidak bertangkai (Gambar 2).

Waktu pembentukan pada buah tumbuhan bakau, mulai dari tunas sampai ke buah dan buah matang atau propagul. Untuk $R$. apiculata dibagi dua fase, yaitu; (a) bunga; (1) dimulai dengan kemunculan tunas pada promordia, (2) pucuk tunas terbentuk dengan panjang 6,90-9,00 mm, (3) kemunculan dua bakal bunga, (4) kemunculan tunas bunga di dalam kelopak bunga, (5) tunas bunga terbentuk panjang 4,00-5,00 $\mathrm{mm}$, tunas bunga berkembang menjadi 12,00-14,00 mm, bunga terbuka, (b) buah; (1) dimulai dengan kemunculan buah pada putik bunga, (2) hipokotil berkembang, (3) propagul matang, dan (4) propagul jatuh.

Ciri umum bunga $R$. mucronata. $R$. mucronata mempunyai ciri gagang bunga seperti cagak, bersifat biseksual, masing-masing menempel pada gagang yang bercabang, panjang 2,72-5,00 $\mathrm{cm}$, letak diketiak daun. Lembaran makhota lonjong, panjang 7,00-9,00 cm, seperti gambar 3. Fase perkembangan bunga $R$. mucronata adalah (1) kemunculan tunas pada promordia, (2) tunas bunga terbentuk dalam kelopak bunga, panjang 8,00-10,00 mm, (3) tunas bunga berkembang menjadi $15-17 \mathrm{~mm}$, (4) bunga terbuka, (5) dan fase buah adalah (1) kemunculan bakal buah panjang 18-20 mm, (2) bakal buah berkembang dengan panjang 38,00-40,00 mm, (3) kemunculan hipokotil panjang 5,00-7,00 cm, (4) hipokotil berkembang dengan panjang 28,00-38,00 cm, (5) hipokotil matang dengan panjang 38,60-70,20 cm, dan (6) hipokotil jatuh (Gambar 3).

Ciri umum bunga $R$. Stylosa. Bunga $R$. stylosa adalah biseksual, masing-masing menempel pada gagang individu yang panjang 2,50-5,10 cm. Letak di ketiak daun. Formasi kelompok 2-16 bunga perkelompok. Kelopak bunga 4 berwarna kuning ke hijauan, panjangnya 13,00 -19,10 mm, jumlah benang sari 8 , panjang $8,00 \mathrm{~mm}$ dan sebuah tangkai putik dengan panjang 3,90 -5,90 cm (Gambar 4).

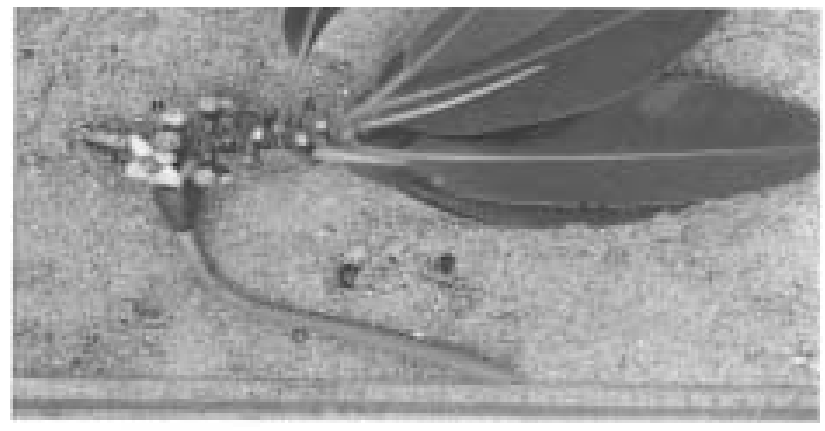

Gambar 2 Contoh bunga $R$. apiculata di kawasan Pulau Unggas, Air Bangis, Pasaman Barat, Sumatera Barat, Indonesia. ATunas bunga, B- Bunga, C- Bunga berkembang, dan DBuah/Propagul. 
Fase bunga pada $R$. stylosa adalah dimulai dari (1) kemunculan tunas pada promordia, (2) tunas bunga terbentuk, panjang 3,95-7,00 $\mathrm{mm}$, (3) tunas bunga berkembang menjadi 9,00-11,10 mm, (4) bunga terbuka, dan fasa buah adalah kemunculan bakal buah panjang 8,00-13,95 mm, (2) bakal buah berkembang dengan panjang 18,05-28,00 mm, (3) kemunculan hipokotil panjang 5,30-7,10 cm, (4) hipokotil berkembang dengan panjang

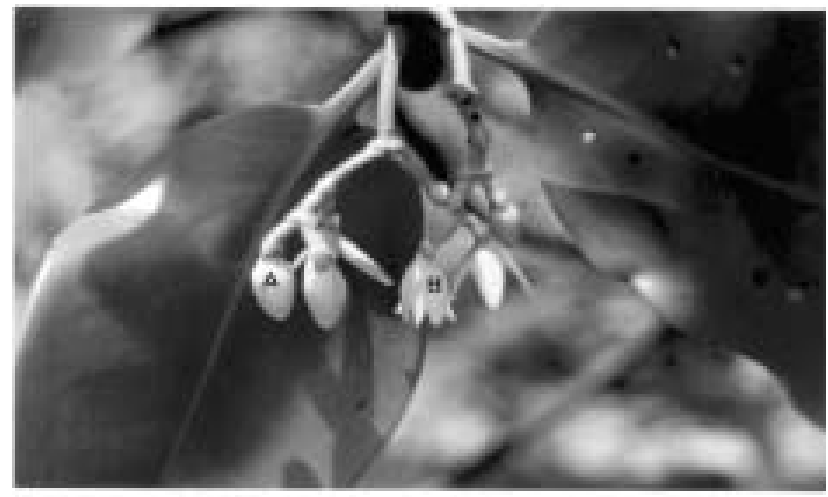

Gambar 3 Contoh bunga $R$. mucronata di kawasan Pulau Unggas Ai Bangis, Pasaman Barat, Sumatera Barat, Indonesia. A- Bunga dan B- Bunga berkembang

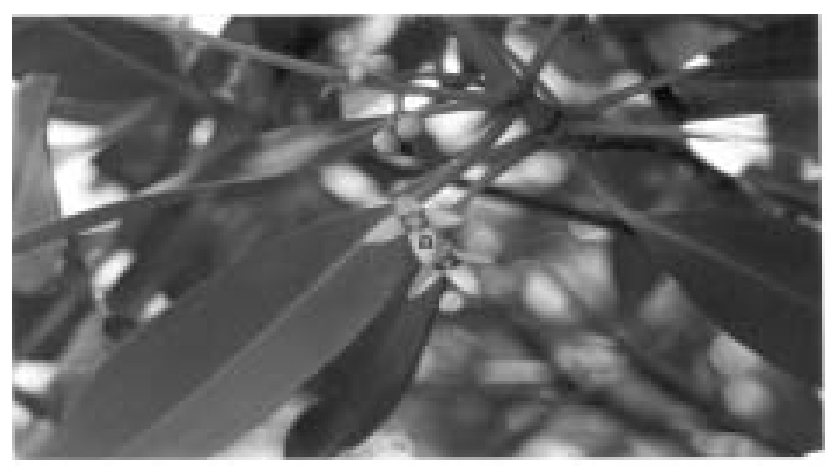

Gambar 4 Contoh bunga $R$. stylosa di kawasan hutan bakau Pulau Unggas, Air Bangis, Pasaman Barat, Sumatra Barat, Indonesia. A- Bunga dan B- Bunga berkembang
28,00-38,10 cm, (5) hipokotil masak dengan panjang 20,00-35,00 cm, dan (6) hipokotil jatuh.

Dari rata-rata jumlah bunga, bunga jatuh, buah, buah jatuh, dan buah matang pada setiap spesies pada tiap pohon adalah seperti pada Tabel 1.

Analisis statistik menunjukkan bahwa produksi bunga, bunga jatuh, buah dan buah jatuh setiap bulan adalah berbeda, seperti produksi bunga tertinggi pada spesies $R$. apiculata adalah pada bulan Februari 2009 dan April 2009, (ANOVA, DMRT, p<0,01) terendah pada bulan Oktober 2009. Untuk $R$. mucronata jumlah produksi bunga tertinggi adalah pada bulan April 1999, (ANOVA, DMRT, p<0,01) dan terendah pada bulan November dan $R$. stylosa produksi jumlah bunga terbanyak adalah pada bulan Maret 2009 dan terendah pada bulan Agustus 2009 (ANOVA, DMRT, $\mathrm{p}<0,01$ ), seperti pada Tabel 2 .

Korelasi produksi bunga, bunga jatuh, buah, buah jatuh dengan curah hujan dan suhu pada tiap-tiap bulan di Pulau Unggas menunjukkan adanya model yang sama untuk setiap spesies. Contohnya untuk $R$. apiculata curah hujan yang tinggi menyebabkan produksi dan terbentuknya bunga bertambah dan juga diikuti dengan banyaknya jumlah bunga jatuh. Faktor lain yang mempengaruhi jumlah bunga jatuh dan buah adalah serangga, seperti yang dilaporkan oleh Saenger et al. 1983, bahwa jumlah bunga yang berkembang menjadi buah adalah rendah hal ini disebabkan oleh jamur, serangga dan juga faktor genetik tumbuhan itu sendiri.

Lamanya waktu dan rata-rata perkembangan "Inflorescence formation" sampai "mature propagule fall" dari bulan ke bulan selama penelitian ini adalah seperti Tabel 3. Pada tumbuhan mangrove waktu perkembangan

Tabel 1 Jumlah bunga, bunga jatuh, buah, buah jatuh dan buah masak berdasarkan spesies di Pulau Unggas, Air Bangis Pasaman Barat, Sumatra Barat, Indonesia

\begin{tabular}{|c|c|c|c|c|c|c|}
\hline Kawasan dan Spesies & Bunga & Bunga Jatuh & Bunga Berkembang & Buah & Buah Jatuh & Propgul Matang \\
\hline \multicolumn{7}{|l|}{ Pulau Unggas: } \\
\hline R. apiculata & $\begin{array}{l}103,40 \\
\pm 22,25\end{array}$ & $\begin{array}{c}81,20 \pm 3,40 \\
(78,30 \%)\end{array}$ & $8,40 \pm 1,08(8,10 \%)$ & $\begin{array}{c}4,10 \pm 1,90 \\
(3,95 \%)\end{array}$ & $\begin{array}{c}3,60 \pm 1,20 \\
(3,47 \%)\end{array}$ & $\begin{array}{c}1,20 \pm 1,20 \\
(1,15 \%)\end{array}$ \\
\hline R. mucronata & $\begin{array}{c}98,70 \\
\pm 12,10\end{array}$ & $\begin{array}{c}83,40 \pm 2,70 \\
(84,33 \%)\end{array}$ & $9,60 \pm 2,32(9,71 \%)$ & $\begin{array}{c}1,40 \pm 1,20 \\
(1,41 \%)\end{array}$ & $\begin{array}{c}0,70 \pm 0,60 \\
(0,71 \%)\end{array}$ & $\begin{array}{c}0,50 \pm 0,35 \\
(0,51 \%)\end{array}$ \\
\hline R. stylosa & $\begin{array}{l}100,10 \\
\pm 24,80\end{array}$ & $\begin{array}{c}92,70 \pm 5,30 \\
(92,61 \%)\end{array}$ & $6,20 \pm 2,14(6,39 \%)$ & $\begin{array}{c}6,80 \pm 1,75 \\
(6,79 \%)\end{array}$ & $\begin{array}{c}3,50 \pm 0,45 \\
(3,49 \%)\end{array}$ & $\begin{array}{c}2,30 \pm 0,40 \\
(1,20 \%)\end{array}$ \\
\hline
\end{tabular}

Tabel 2 Produksi jumlah bunga, bunga jatuh, buah dan buah jatuh setiap bulan berdasarkan spesies di Pulau Unggas Air Bangis, Pasaman Barat, Sumatra Barat, dan menunjukkan perbedaan pada $\mathrm{p}<0,01$ (ANOVA, post-hoc Duncans Multiple Range Test), iaitu a $>b>c ;$ ns - tidak signifikan

\begin{tabular}{|c|c|c|c|c|}
\hline Kawasan/Spesies & Bunga & Bunga jatuh & Buah & Buah jatuh \\
\hline \multicolumn{5}{|l|}{ Pulau Unggas: } \\
\hline R. apiculata & $\begin{array}{c}5,12 \pm 0,45^{\mathrm{a}} \\
(4,20-5,84)\end{array}$ & $\begin{array}{c}3,74 \pm 0,24^{b} \\
(3,26-4,22)\end{array}$ & $\begin{array}{c}0,24 \pm 0,06^{\mathrm{c}} \\
(0,10-0,38)\end{array}$ & $\begin{array}{c}0,23 \pm 0,06^{\mathrm{c}} \\
(0,10-0,37)\end{array}$ \\
\hline R. mucronata & $\begin{array}{c}4,73 \pm 0,40^{\mathrm{a}} \\
(3,63-5,53)\end{array}$ & $\begin{array}{l}4,14 \pm 0,34^{\mathrm{a}} \\
(3,46-4,83)^{\mathrm{a}}\end{array}$ & $\begin{array}{c}0,29 \pm 0,06^{\mathrm{b}} \\
(0,17-0,43)\end{array}$ & $\begin{array}{c}0,04 \pm 0,02^{\mathrm{c}} \\
(0,01-0,09)\end{array}$ \\
\hline R. stylosa & $\begin{array}{c}5,09 \pm 0,43^{\mathrm{a}} \\
(4,24-5,94)\end{array}$ & $\begin{array}{c}4,05 \pm 0,34^{\mathrm{a}} \\
(3,37-4,73)\end{array}$ & $\begin{array}{c}0,08 \pm 0,03^{b} \\
(0,01-0,15)\end{array}$ & $\begin{array}{c}0,02 \pm 0,01^{\mathrm{b}} \\
(0,01-0,05)\end{array}$ \\
\hline
\end{tabular}


Tabel 3 Lamanya waktu (bulan) rata-rata perkembangan dari "Inflorescence formation" sampai "mature propagule fall" berdasarkan spesies di Pulau Unggas di Air Bangis Pasaman Barat, Sumatra Barat

\begin{tabular}{|c|c|c|c|c|c|c|}
\hline $\begin{array}{l}\text { Kawasan dan } \\
\text { Spesies }\end{array}$ & $\begin{array}{l}\text { Pembentukan } \\
\text { Inflorescence } \\
\text { (Inflorescence } \\
\text { formation) }\end{array}$ & $\begin{array}{c}\text { Perkembangan } \\
\text { Tunas } \\
\text { (Buddevelopment) }\end{array}$ & $\begin{array}{c}\text { Bunga } \\
\text { Berkembang } \\
\text { (Anthesis) }\end{array}$ & $\begin{array}{c}\text { Perkembangan Buah } \\
\text { (Fruit development) }\end{array}$ & $\begin{array}{c}\text { Perkembangan } \\
\text { Propagul } \\
\text { (Propagule } \\
\text { development) }\end{array}$ & $\begin{array}{c}\text { Propagul } \\
\text { Masak } \\
\text { (Mature } \\
\text { propagule fall) }\end{array}$ \\
\hline \multicolumn{7}{|l|}{ Pulau Unggas: } \\
\hline R. apiculata & $\begin{array}{c}\text { Feb } 08-\text { Mar } 08 \\
(1,98 \pm 1,04)\end{array}$ & $\begin{array}{c}\text { Apr } 08-\text { Feb } 09 \\
(10,12 \pm 0,900)\end{array}$ & $\begin{array}{c}\text { Mar } 09-\text { Jun } 09 \\
(3,87 \pm 0,85)\end{array}$ & $\begin{array}{c}\text { Jul } 09-\text { Sep } 09 \\
(3,08 \pm 0,90)\end{array}$ & $\begin{array}{c}\text { Okt } 09-\text { Des } 09 \\
(3,01 \pm 0,62)\end{array}$ & $\begin{array}{c}\text { Des 09 } \\
22,06 \pm 0,86\end{array}$ \\
\hline R. mucronata & $\begin{array}{c}\text { Feb } 08-\text { Mei } 08 \\
(1,89 \pm 0,87)\end{array}$ & $\begin{array}{c}\text { Jun } 08-\text { Okt } 08 \\
(5,95 \pm 0,92)\end{array}$ & $\begin{array}{l}\text { Nov } 098-\text { Mar } 09 \\
\quad(3,27 \pm 0,65)\end{array}$ & $\begin{array}{c}\text { Apr } 09-\text { Jul } 09 \\
(3,90 \pm 0,45)\end{array}$ & $\begin{array}{c}\text { Agus } 09-\text { Nov } 09 \\
(3,91 \pm 0,80)\end{array}$ & $\begin{array}{c}\text { Nov 09 } \\
(18,85 \pm 0,74)\end{array}$ \\
\hline R. stylosa & $\begin{array}{c}\text { Feb } 08-\text { Mar } 08 \\
(2,18 \pm 1,20)\end{array}$ & $\begin{array}{c}\text { Apr } 08-\text { Mar } 09 \\
(11,21 \pm 0,80)\end{array}$ & $\begin{array}{c}\text { Apr 09 - Jul 09 } \\
(3,25 \pm 1,08)\end{array}$ & $\begin{array}{c}\text { Agus } 09-\text { Sep } 09 \\
(2,09 \pm 0,60)\end{array}$ & $\begin{array}{c}\text { Okt } 09 \text { - Des } 099 \\
(2,98 \pm 0,86)\end{array}$ & $\begin{array}{c}\text { Des } 09 \\
(21,71 \pm 0,91)\end{array}$ \\
\hline
\end{tabular}

Tabel 4 Waktu berbunga dan berbuah dari spesies tumbuhan di hutan bakau

\begin{tabular}{|c|c|c|c|c|c|}
\hline Spesies & Kawasan & waktu penelitian & waktu berbunga & waktu berbuah & Sumber \\
\hline \multirow[t]{2}{*}{ R. apiculata } & Ranong, Thailand & 12 bulan & Des.-Jan. & April-Juli & Kongsangchai et al. (1982) \\
\hline & P.Unggas & 24 bulan & Mar.-Juni & Okt.-Des. & Penelitian ini \\
\hline \multirow[t]{4}{*}{ R. mucronata } & Ranong, Thailand & 12 bulan & Sept.-Jan. & Mar.-Jun. & Kongsangchai et al. (1982) \\
\hline & Prapat, Bali & 24 bulan & - & Sept.-Mar. & Hachinohe dan Suko (1997) \\
\hline & Bali dan Lombok & 16 bulan & Agus.-Des. & Okt.-Des. & Kitamura et al. (1997) \\
\hline & P. Unggas & 24 bulan & Nov.-Mar. & Agus-Des. & Penelitian ini \\
\hline \multirow[t]{2}{*}{ R. stylosa } & Jepang & 24 bulan & Feb.-Mei & Juli.-Okt. & Nakamura (1982) \\
\hline & P. Unggas & 24 bulan & April.-Juli & Okt.-Des. & Penelitian ini \\
\hline
\end{tabular}

bunga sampai buah masak atau propagul yang muda jatuh pada $R$. apiculata dan $R$. mucronata memakan waktu sampai 2 tahun, dimana waktu perkembangan bunga adalah 4-6 bulan. Kongsangchai et al. 1992, menyatakan bahwa lamanya kisaran produksi mangrove di Ranong, Thailand pada $R$. apiculata adalah 18 bulan dan $R$. mucronata 17 bulan.

Kitamura et al. 1983, dalam kajiannya menyatakan bahwa waktu $R$. apiculata berbunga di Bali dan Lombok adalah sepanjang tahun dan musim berbuah pada bulan Desember sampai Maret tiap tahunnya. Lama bunga berkembang sampai menjadi propagul matang adalah 5-6 bulan, dengan panjang propagul 50,00-70,00 $\mathrm{cm}$ dan diameter buah 1,30-1,70 cm, R. mucronata berbunga sepanjang tahun, musim puncak berbunga bulan Agustus sampai Desember. Musim berbuah mulai pada bulan Oktober. Desember terutamanya mulai musim hujan (Tabel 4). Perbandingan dengan penelitian ini menunjukkan waktu berbunga dan berbuah adalah berbeda, namun musim mulai berbuah yaitu pada mulai musim hujan, dimana waktu berbuah pada $R$. mucronata di Pulau Unggas adalah pada bulan Agustus-Desember (Tabel 4) dengan curah hujan $89,00-433,00 \mathrm{~mm}$

\section{SIMPULAN}

Musim berbunga dan berbuah terjadi sepanjang tahun, musim puncak berbuah untuk $R$. apiculata dari September-Desember, $R$. mucronata adalah dari bulan Juli-November, dan R. stylosa dari Oktober-Desember. Faktor lingkungan seperti curah hujan, suhu udara dan kelembaban udara mempengaruhi musim berbunga dan berbuah pada hutan bakau. Rentang waktu mulainya bunga berkembang sampai propagul matang adalah untuk ketiga spesies tersebut $R$. mucronata 18.85 bulan, $R$. apiculata 22,06 bulan dan $R$. stylosa 21,70 bulan.

\section{UCAPANTERIMAKASIH}

Penulis menyampaikan ucapan terima kasih kepada Ketua Badan Pengurus Yayasan Pendidikan Bung Hatta, Rektor Universitas Bung Hatta dan Pemerintah Daerah Kabupaten Pasaman Barat, Camat Kecamatan Sungai Beremas, Air Bangis atas segala bantuan yang diberikan secara materil dan moril dan staf Pusat Studi Pesisir dan Kelautan Universitas Bung Hatta Padang.

\section{DAFTAR PUSTAKA}

Chan, H.T., Ong, T.E., Gong, W.K. \& Sasekumar, A. 1993. The socio-economic, ecological and environmental value of mangrove ecosystem in Malaysia and the present state of conservation. Di dalam: Cluugh, B. F. (ed). The economic and environmental value of mangrove Forest and their Present state conservation in the South-East Asia/Pacifik Region, ISME Mangrove Ecosystem Technical Report 1: 41-81.

Citron, G. \& Novelli, Y.S. 1984. Methode for studying mangrove structure. Di dalam: Snedaker, S.C. and Snedaker, J.G. (ed). The mangrove Ecosystem; Research Methode, UNESCO.

Hutching, P. \& Saenger, P. 1987. Ecology mangrove. australia ecology series. university of queensland press. ST. Incia.

Japar Sidik, B. 1989. Studies on leaf litter decomposition of the mangrove, Rhizophora apiculata BL. Tesis Pengajian Siswazah. Malaysia: USM.

Kamal, E. 1998. Kajian ekologi hutan paya bakau di Air Bangis, Pasaman, Sumatera Barat, Indonesia.Universiti Putra Malaysia. Laporan Penelitian. Malaysia. Pusat Pengajian Siswazah, Universiti Putra Malaysia.

Kamal, E. 2003. Komposisi dan profil hutan mangrove Pulau Unggas, Air Bangis, Pasaman. Jurnal Mangrove dan Pesisir. Pusat Kajian Mangrove dan Pesisir. Univeritas Bung Hatta. 1 (III): $1-7$.

Kamal, E. 2005. Kajian ekologi hutan paya bakau di Air Bangis, Pasaman Barat, Sumatera Barat, Indonesia. Pengajian Siswazah Universiti Putra Malaysia, Malaysia: UPM. 
Kitamura, S., Anwar, C., Chaniago, A. \& Baba, S. 1997. Handbook of mangrove in Indonesia Bali and Lombok. The Development of Sustainable Mangrove Management Project. Ministry of Forestry Indonesia and Japan International Cooperation Agency.

Kongsangchai, J., Panithusuko, S., Havanond, S., Laengthanawatankul, J., Supaphibool, K. \& Panitchar, S. 1982. Studies on phenology of some mangrove species in Thailand. In Proc. of NRCT-JSPS Rattanakosin Bicenttennial Join Seminar on Sciens and Mangrove Resources, Phuket, Thailand, 2-6 August 1982.
Muthalib, A.S. \& Hayashi, S. 1994. Observasi fenology bunga mangrove di kawasan hutan taman raya Ngurah Rai, Denpasar, Bali. Prosedings Seminar V Ekosistem Mangrove. Jember 3 Agustus, 1994.

Nakamura, T. 1982. Morphological and ecolocal studies of some mangrove leaves and flower. In Proc. Of NRCT-JSPS Rattanakosin Bicenttennial Join Seminar on Sciens and Mangrove Resources, t, Phuket, Thailand, 2 - 6 August 1982.

Saenger, P., Hegerl, E.J. \& Davis, D.J. S. 1983. Global status of mangrove ecosystem. Commision on ecology paper number 3. International union conservation of natural resources, Switzerland: IUCN. 